\title{
Association between hypertension and insulin resistance in non-diabetic adult populations: a community-based study from the Iran
}

\author{
Fatemeh Samiee Rad®1, Sonia Oveisi®1, Hamid Reza Javadi®1, Ameneh Barikani ${ }^{1}$, \\ Mohammad Sofiabadi ${ }^{2}$ \\ ${ }^{1}$ Metabolic Diseases Research Center, Research Institute for Prevention of Non-Communicable Diseases, \\ Qazvin University of Medical Sciences, Qazvin, Iran \\ ${ }^{2}$ Cellular and Molecular Research Center, Research Institute for Prevention of Non-Communicable Disease, \\ Qazvin University of Medical Sciences, Oazvin, Iran
}

\begin{abstract}
Background and objectives: High blood pressure increases the probability of insulin resistance and hyperinsulinemia. Also, insulin resistance can be defined as a risk factor for hypertension. The present study investigated the relationship between hypertension and insulin resistance in non-diabetic participants who were referred to Qazvin Metabolic Diseases Center.

Material and methods: In this cross sectional study, 1103 participants (111 non-diabetic with newly diagnosed hypertension and 992 normotensive subjects aged $\geq 20$ years) were enrolled from September 2014 to April 2016 in Qazvin (Iran). Systolic and diastolic blood pressure, insulin resistance, waist circumference, body mass index, triglycerides, cholesterol, LDL-cholesterol, fasting blood glucose (FBG) were measured. Fasting triglyceride to highdensity lipoprotein cholesterol ratio (TG/HDL-C) was used as a surrogate of insulin resistance. Data were analyzed using SPSS software and $\mathrm{p}<0.05$ was assumed as significant level.

Results: Ten percent of all participants had hypertension. TG/HDL-C was $3.78 \pm 3.28$ in non-HTN and $5.76 \pm 5.35$ in HTN participants $(\mathrm{p}<0.001)$. The frequency of all cardio-metabolic risk factors (except HDL cholesterol level) was higher in hypertensive group, after adjusting for age and gender $(\mathrm{p}<0.001)$.

Conclusion: Based on these results, essential hypertension is associated with a higher prevalence of hyperinsulinemia and insulin resistance in the non-diabetic community in Iran.
\end{abstract}

Key words: hypertension; insulin resistance; non-diabetic

Arterial Hypertens. 2020, vol. 24, no. 4, pages: 159-166

DOI: 10.5603/AH.a2020.0020

\section{Introduction}

Hypertension (HTN) is one of the most important and constantly increasing global health problems [1]. Hypertension is a well-known modifiable risk factor for cardiovascular diseases, chronic renal failure, stroke, and a high morbidity rate [2]. Cardio- vascular diseases affect more than 1 billion people worldwide. They are responsible for more than 10 million preventable deaths globally each year [3]. A linear association is between cardiovascular and cerebrovascular events with a wide spectrum of blood pressure elevation in clinical presentation severity. In subjects aged between 40 and 70 years,

Address for correspondence: Mohammad Sofiabadi, Cellular and Molecular Research Center, Research Institute for Prevention of Non-Communicable Disease, Qazvin University of Medical Sciences, Bahonar St., Qazvin, Iran; Tel: (+98) 33330061; e-mail: fsamieerad@gmail.com 
each $20-\mathrm{mm} \mathrm{Hg}$ increase in systolic or $10-\mathrm{mm} \mathrm{Hg}$ in diastolic blood pressures doubles risk of cardiovascular and cerebrovascular events $[4,5]$. Around the world, it is estimated that the prevalence of hypertension will increase up to $>1.5$ billion in the year 2025 [6]. Hypertension is present in more than $50 \%$ of patients with diabetes mellitus (DM) and contributes significantly to both micro and macrovascular disease in diabetic patients [7]. Similar to the prevalence of type 2 diabetes in the Middle East, HTN is rising and it is estimated to be an important public health problem in this region [8]. The common findings in hypertension are hyperinsulinemia and insulin resistance $[9,10]$. It has been estimated that about half of patients with essential hypertension are insulin-resistant [11]. Insulin resistance is defined as a decrease in the physiological response to insulin and compensatory over-secretion of insulin. In this situation, the transport of glucose into the skeletal muscle and fat cells are impaired. Therefore, pure results are hyperinsulinemia and hyperglycemia [12]. Hyperinsulinemia may directly promote atherosclerosis by enhancing LDL-cholesterol accumulation in vessel walls, vascular smooth muscle migration, proliferation, augmenting connective tissue synthesis in the arterial wall, and decreasing the regression of lipid plaques [13]. There are several reports that there is a link between essential hypertension and insulin resistance; however, the underlying pathogenesis seems inherently contradictory [14]. It is important that more studies proposed for assaying the association between blood pressure elevation and other underlying pathologies $[15,16]$. In the Middle East countries due to demographic transition and lifestyle westernization, the incidence of obesity and associated complications are increased $[3,17]$. Similar to other countries in the world, the prevalence of hypertension and metabolic syndrome is growing in Iran, so that the prevalence of hypertension has been reported by about $20 \%$ and $23 \%$ in men and women, respectively (2004-2006). Total prevalence is about $32.5 \%[18,19]$. The current study was designed to evaluate the association between essential hypertension and insulin resistance among non-diabetic adult participants that are newly diagnosed as hypertensive in the Qazvin province of Iran.

\section{Material and methods}

\section{Data sets and subjects}

This cross-sectional study included 1103 volunteers (111 non-diabetic patients with newly diagnosed hypertension and 992 normotensive individuals aged 20 years or older) who were referred to the Qazvin Metabolic Diseases Center (Iran) from September 2014 to April 2016.

All participants (526 men and 577 women) signed written informed consent before enrollment. Their responses were confidential. The ethics board of the Qazvin University of Medical Science approved the study. Participants were selected by a multistage cluster random sampling method. The inclusion criteria were newly diagnosed hypertension and normal population aged 20 years or older in the Qazvin. Exclusion criteria were: smoking, malignant or accelerated hypertension, heart failure, cardiomyopathy, peripheral vascular disease, past medical history of cardiovascular or cerebrovascular disease, or any secondary hypertension (liver and kidney diseases, hyperthyroidism, or aldosteronism, etc.).

\section{Data collection}

The demographic data, such as age, gender, prior history of treatment for diabetes, and hypertension were collected with interview sessions. The anthropometric characteristics (weight, height, waist circumference, and hip) were measured by standard methods. Bodyweight was measured to the nearest $0.1 \mathrm{~kg}$ with a balanced-beam scale while wearing light clothing, and height was measured with a stadiometer to the nearest $0.5 \mathrm{~cm}$. Body mass index (BMI) was calculated based on the weight/(height $)^{2}$ formula. Participants with a BMI between 25 and $29.9 \mathrm{~kg} / \mathrm{m}^{2}$ were considered overweight. Obesity was defined as BMI of more than $30 \mathrm{~kg} / \mathrm{m}^{2}$. Waist circumference between the lowest rib and the iliac crest, at the level of the umbilicus, was measured in duplicate to the nearest millimeter using flexible tape. Waist circumference (WC) equal or more than $85 \mathrm{~cm}$ in females and equal or more than $90 \mathrm{~cm}$ in males was considered central obesity. Blood pressure was measured by a calibrated sphygmomanometer. Systolic (Korotkoff phase I) and diastolic (Korotkoff phase V) blood pressure was measured twice a day on the left upper arm and the average of the two amounts was considered [20].

\section{Biochemical measurement}

Venous blood samples were collected from all participants after 12 hours of overnight fast. Blood samples were stored at $70^{\circ} \mathrm{C}$. The serum was separated by centrifugation at $3000 \mathrm{rpm}$ for $15 \mathrm{~min}$. Total cholesterol (TC), low-density lipoprotein cholesterol (LDL-C), triglycerides (TG), glucose, and high-density lipoprotein (HDL-C) were measured by the calibrated automatic biochemical analyzer 
(HITECH 7080, Tokyo, Japan). Enzymatic methods were applied to estimate levels of TC, LDL, glucose, and TG. Insulin levels were measured with a sensitivity of $0.25(\mu \mathrm{U} / \mathrm{mL})$ via an electrochemiluminescence immunoassay (ECLIA). The ratio of triglyceride (TG) to high-density lipoprotein (HDL-C) (TG/HDL-C) was used as a measure of insulin resistance. According to several studies' definitions, insulin-resistant (IR) was TG/HDL-C ratio greater than 3.0, and insulin-sensitive (IS) was TG/HDL-C ratio less than $2.0[10,21]$. LDL-C was calculated using Friedwald's formula (TG $\leq 400 \mathrm{mg} / \mathrm{dL}$ ). Diagnosis of the cardiometabolic risk factors in adults including women and men is based on revised $\mathrm{Na}$ tional Cholesterol Education Program-Adult Treatment Panel III (NCEP/ATPIII) and World Health Organization (WHO) criteria. Metabolic syndrome was defined by the presence of three or more following findings: (1) abdominal obesity ( $\mathrm{WC} \geq 90 \mathrm{~cm}$ in men and $\geq 85 \mathrm{~cm}$ in women) or BMI $>30$, (2) a high triglyceride level $\geq 150 \mathrm{mg} / \mathrm{dL}$ or medical therapy for hypertriglyceridemia; (3) a low HDL cholesterol level $(<40 \mathrm{mg} / \mathrm{dL}$ for men and $<50 \mathrm{mg} / \mathrm{dL}$ for women); (4) high blood pressure (systolic $\geq 130$ $\mathrm{mm} \mathrm{Hg}$ and diastolic $\geq 85 \mathrm{~mm} \mathrm{Hg}$ or antihypertensive medical therapy; and (5) a high fasting plasma glucose concentration $\geq 100 \mathrm{mg} / \mathrm{dL}$ or medical treatment for type $2 \mathrm{DM}[21]$.

\section{Statistical analysis}

Chi-square and odds-ratio tests were used to compare qualitative parameters. To compare quantitative variables, we used unpaired student t test or Mann-Whitney test, as appropriate. For a comparative analysis of quantitative variables between HTN or insulin resistance subgroups, one-way ANOVA was used. To control confounding variables such as age and gender, a partial correlation by Spearman $\rho$ was applied to find a significant correlation between clinical and biochemical characteristics. IBM SPSS Statistics 22.0 for Windows (IBM Corp., Armonk, NY, USA) was used for all the statistical analyses, and $\mathrm{P}<0.05$ was assumed as significant differences.

\section{Results}

\section{Demographical characteristic of participants} Of the total of 1103 participants, $47.7 \%$ were male and $52.3 \%$ were female. There were $10 \%$ participants with hypertension. The mean age of the subjects was $40.08 \pm 10.33$ years (Tab. 1 ).

\section{Comparative biochemical characteristics of participants based on gender}

Comparing the two sexes except for the mean cholesterol, LDL, and systolic and diastolic pressure, all of the variables had significant differences $(\mathrm{p}<0.00)$ (Tab. 2).

Table 1. Age distribution of the study population

\begin{tabular}{|l|c|c|c|}
\hline Age (yrs) & Male & Female & Total \\
\hline $20-29$ & 78 & 118 & $17.8 \%$ \\
\hline $30-39$ & 83 & 184 & $24.3 \%$ \\
\hline $40-49$ & 261 & 218 & $43.6 \%$ \\
\hline $50-59$ & 82 & 38 & $10.9 \%$ \\
\hline $60-70$ & 23 & 14 & $7.9 \%$ \\
\hline
\end{tabular}

Table 2. Comparison (mean \pm SD) of the clinical and biochemical characteristics of participants based on gender

\begin{tabular}{|c|c|c|c|c|}
\hline Variables & $\begin{array}{c}\text { Male } \\
(\mathrm{n}=527)\end{array}$ & $\begin{array}{c}\text { Female } \\
(\mathrm{n}=572)\end{array}$ & $\mathbf{F}$ & p value \\
\hline WC $[\mathrm{cm}]$ & $92.0 \pm 0.40302$ & $87.2669 \pm 0.46560$ & 20.086 & 0.000 \\
\hline BMI $\left[\mathrm{kg} / \mathrm{m}^{2}\right]$ & $25.1502 \pm 0.16170$ & $26.6907 \pm 0.20338$ & 30.332 & 0.000 \\
\hline $\mathrm{TG}[\mathrm{mg} / \mathrm{dL}]$ & $166.4722 \pm 5.26090$ & $128.7887 \pm 2.92453$ & 26.683 & 0.000 \\
\hline $\mathrm{TC}[\mathrm{mg} / \mathrm{dL}]$ & $184.3808 \pm 1.67147$ & $182.2814 \pm 1.71750$ & 0.034 & 0.381 \\
\hline $\mathrm{HDL}[\mathrm{mg} / \mathrm{dL}]$ & $38.4333 \pm 0.37941$ & $45.3373 \pm 0.46345$ & 18.871 & 0.000 \\
\hline LDL [mg/dL] & $109.3038 \pm 1.07617$ & $104.9747 \pm 1.11455$ & 0.744 & 0.389 \\
\hline FBG [mg/dL] & $99.6729 \pm 1.19488$ & $99.8213 \pm 1.33409$ & 5.286 & 0.000 \\
\hline Insulin [mU/mL] & $11.8186 \pm 0.35082$ & $12.2111 \pm 0.29846$ & 0.120 & 0.002 \\
\hline $\mathrm{SBP}[\mathrm{mg} \mathrm{Hg}]$ & $115.4411 \pm 0.74522$ & $109.5407 \pm 0.74548$ & 0.064 & 0.800 \\
\hline $\mathrm{DBP}[\mathrm{mg} \mathrm{Hg}]$ & $73.7500 \pm 0.50089$ & $69.6267 \pm 0.49482$ & 0.559 & 0.455 \\
\hline
\end{tabular}


Table 3. Comparison (mean \pm SD) of the clinical and biochemical characteristics in male patients with hypertension (HTN) and without hypertension (non-HTN)

\begin{tabular}{|c|c|c|c|c|}
\hline Variables & $\begin{array}{l}\text { Non-HTN } \\
(\mathrm{n}=371)\end{array}$ & $\begin{array}{c}\text { HTN } \\
(n=153)\end{array}$ & $\mathbf{F}$ & $\mathrm{p}$ value \\
\hline WC $[\mathrm{cm}]$ & $\begin{array}{c}90.0243 \\
\pm 0.44029\end{array}$ & $\begin{array}{c}96.7763 \\
\pm 0.76870\end{array}$ & 0.569 & 0.000 \\
\hline BMI $\left[\mathrm{kg} / \mathrm{m}^{2}\right]$ & $\begin{array}{c}24.3947 \\
\pm 0.18491\end{array}$ & $\begin{array}{c}26.9652 \\
\pm 0.28480\end{array}$ & 0.001 & 0.000 \\
\hline $\mathrm{TG}[\mathrm{mg} / \mathrm{dL}]$ & $\begin{array}{c}148.3433 \\
\pm 4.73326\end{array}$ & $\begin{array}{c}212.2886 \\
\pm 13.54566\end{array}$ & 19.630 & 0.000 \\
\hline $\mathrm{TC}[\mathrm{mg} / \mathrm{dL}]$ & $\begin{array}{c}179.4087 \\
\pm 1.84096\end{array}$ & $\begin{array}{c}196.7477 \\
\pm 3.74389\end{array}$ & 3.313 & 0.000 \\
\hline $\mathrm{HDL}$ [mg/dL] & $\begin{array}{c}38.9423 \\
\pm 0.44784\end{array}$ & $\begin{array}{c}36.9736 \\
\pm 0.71659\end{array}$ & 0.008 & 0.019 \\
\hline LDL [mg/dL] & $\begin{array}{c}106.1420 \\
\pm 1.21572\end{array}$ & $\begin{array}{c}117.2852 \\
\pm 2.14042\end{array}$ & 1.016 & 0.000 \\
\hline $\mathrm{FBG}[\mathrm{mg} / \mathrm{dL}]$ & $\begin{array}{c}96.3807 \\
\pm 0.95700\end{array}$ & $\begin{array}{c}107.5174 \\
\pm 3.35732\end{array}$ & 13.125 & 0.000 \\
\hline Insulin [mU/mL] & $\begin{array}{c}11.0215 \\
\pm 0.43861\end{array}$ & $\begin{array}{c}13.8774 \\
\pm 0.54260\end{array}$ & 1.294 & 0.000 \\
\hline SBP [mg Hg] & $\begin{array}{c}107.4124 \\
\pm 0.54261\end{array}$ & $\begin{array}{c}135.1765 \\
\pm 1.10516\end{array}$ & 7.937 & 0.000 \\
\hline $\mathrm{DBP}$ [mg Hg] & $\begin{array}{c}68.6523 \\
\pm 0.40689\end{array}$ & $\begin{array}{c}86.1111 \\
\pm 0.74798\end{array}$ & 3.219 & 0.000 \\
\hline
\end{tabular}

WC — waist circumference; BMI — body mass index; TG — triglycerides; TC — total cholesterol; HDL — high density lipoprotein; LDL — low density lipoprotein; FBG — fasting blood glucose; SBP — systolic blood pressure; DBP — diastolic blood pressure

\section{Clinical and biochemical characteristics in non-HTN and HTN individuals}

In males, there were significant differences between patients with hypertension (HTN) and non-hypertensive participants in WC, BMI, lipid profiles (including: TG, TC, HDL-C, and LDL-C), fasting blood glucose (FBG), insulin level, systolic, and diastolic blood pressure $(\mathrm{p}<0.00)$ (Tab. 3).

In women participants, there were significant differences between HTN non-HTN participants in all mentioned variables, except for total cholesterol and LDL-C $(\mathrm{p}<0.00)($ Tab. 4).

\section{Clinical and biochemical characteristics in insulin-resistant and insulin-sensitive individuals}

There were significant differences in insulin resistance and biochemical variables such as WC, BMI, lipid profiles, FBG (except in males), and insulin level, in both male and female groups, between insulin resistant and insulin-sensitive participants $(\mathrm{p}<0.000)$.

Also, in both genders, the systolic (M: $116.82 \pm$ 1 vs. $112.72 \pm 1.07 \mathrm{~mm} \mathrm{Hg}, \mathrm{F} ; 113.67 \pm 1.29$ vs. $107.18 \pm 0.91 \mathrm{~mm} \mathrm{Hg}$ ) and diastolic (M: $74.49 \pm$ 0.57 vs. $72.19 \pm 0.72 \mathrm{~mm} \mathrm{Hg}, \mathrm{F} ; 72.51 \pm 0.86$ vs.
$68.1 \pm 0.6 \mathrm{~mm} \mathrm{Hg}$ ) blood pressure were significantly higher in insulin-resistant patient than in insulinsensitive participants $(\mathrm{p}<0.00)($ Tab. 5, 6).

\section{Cardio-metabolic factors in HTN vs. non-HTN participants}

The mean of TG/HDL as an index of insulin resistance or sensitivity was $3.97 \pm 3.59$ among all of the participants. This index was different between HTN and non-HTN participants. TG/HDL-C was $3.78 \pm$ 3.28 in non-HTN and $5.76 \pm 5.35$ in HTN participants $(\mathrm{p}<0.001)$. Overall, the correlation between HTN and cardio-metabolic factors in both genders was considerable; the frequency of all cardiometabolic risk factors (except HDL and TC level) was higher after adjusting for age and gender in the hypertensive group (Tab. 5, 6).

\section{Discussion}

The prevalence of high blood pressure is increasing rapidly across the world, especially in developing countries like Iran. This epidemiological transmission in developing countries leads to an alarming increase in non-transmitted diseases, especially diabetes 
Table 4. Comparison (mean \pm SD) of the clinical and biochemical characteristics in female patients with hypertension (HTN) and without hypertension (non-HTN)

\begin{tabular}{|l|c|c|c|c|}
\hline Variables & $\begin{array}{c}\text { Non-HTN } \\
(\mathbf{n}=\mathbf{4 7 4})\end{array}$ & $\begin{array}{c}\text { HTN } \\
(\mathbf{n}=\mathbf{1 0 2})\end{array}$ & F & p value \\
\hline WC $[\mathrm{cm}]$ & $86.1540 \pm 0.50098$ & $92.4455 \pm 1.09729$ & 0.131 & 0.000 \\
\hline BMI $\left[\mathrm{kg} / \mathrm{m}^{2}\right]$ & $26.1891 \pm .22249$ & $29.0764 \pm 0.43878$ & 0.398 & 0.000 \\
\hline TG $[\mathrm{mg} / \mathrm{dL}]$ & $123.1947 \pm 3.11338$ & $155.2434 \pm 7.54399$ & 3.147 & 0.000 \\
\hline TC $[\mathrm{mg} / \mathrm{dL}]$ & $181.5674 \pm 1.81223$ & $185.5929 \pm 4.32648$ & 0.750 & 0.325 \\
\hline HDL $[\mathrm{mg} / \mathrm{dL}]$ & $45.8158 \pm 0.50983$ & $43.0636 \pm 1.10976$ & 0.539 & 0.026 \\
\hline LDL $[\mathrm{mg} / \mathrm{dL}]$ & $104.2556 \pm 1.21746$ & $108.5172 \pm 2.78362$ & 0.321 & 0.163 \\
\hline FBG $[\mathrm{mg} / \mathrm{dL}]$ & $98.2074 \pm 1.38064$ & $107.5455 \pm 3.91051$ & 8.005 & 0.026 \\
\hline Insulin $[\mathrm{mU} / \mathrm{mL}]$ & $11.7356 \pm 0.32458$ & $14.5660 \pm 0.71456$ & 0.086 & 0.000 \\
\hline SBP $[\mathrm{mg} \mathrm{Hg}]$ & $103.6498 \pm 0.54905$ & $137.1569 \pm 1.47046$ & 2.263 & 0.000 \\
\hline DBP $[\mathrm{mg} \mathrm{Hg}]$ & $65.9599 \pm 0.37506$ & $86.6667 \pm 1.14756$ & 10.517 & 0.000 \\
\hline
\end{tabular}

WC — waist circumference; BMI — body mass index; TG — triglycerides; TC — total cholesterol; HDL — high density lipoprotein; LDL — low density lipoprotein; FBG — fasting blood glucose; SBP — systolic blood pressure; DBP - diastolic blood pressure

Table 5. Comparison (mean \pm SD) of the clinical and biochemical characteristics in insulin-resistant and insulin-sensitive male individuals

\begin{tabular}{|l|c|c|c|c|}
\hline Variables & $\begin{array}{c}\text { TG/HDL } \leq \mathbf{3} \\
\text { (n= 199) }\end{array}$ & $\begin{array}{c}\text { TG/HDL > 3 } \\
\text { (n= 321) }\end{array}$ & F & p value \\
\hline WC $[\mathrm{cm}]$ & $89.2778 \pm 0.67473$ & $93.6688 \pm 0.48313$ & 2.956 & 0.000 \\
\hline BMI $\left[\mathrm{kg} / \mathrm{m}^{2}\right]$ & $23.9278 \pm 0.27410$ & $25.8763 \pm 0.18906$ & 6.456 & 0.000 \\
\hline TG $[\mathrm{mg} / \mathrm{dL}]$ & $90.9196 \pm 1.57376$ & $208.9938 \pm 6.05391$ & 106.618 & 0.000 \\
\hline TC $[\mathrm{mg} / \mathrm{dL}]$ & $171.3769 \pm 2.30311$ & $191.4966 \pm 2.08855$ & 3.041 & 0.000 \\
\hline HDL $[\mathrm{mg} / \mathrm{dL}]$ & $44.6157 \pm 0.56950$ & $34.6006 \pm 0.36586$ & 9.608 & 0.000 \\
\hline LDL $[\mathrm{mg} / \mathrm{dL}]$ & $103.1734 \pm 1.65782$ & $113.3184 \pm 1.35321$ & 0.000 & 0.000 \\
\hline FBG $[\mathrm{mg} / \mathrm{dL}]$ & $97.3714 \pm 1.22056$ & $100.9121 \pm 1.77307$ & 3.712 & 0.149 \\
\hline Insulin $[\mathrm{mU} / \mathrm{mL}]$ & $10.5172 \pm 0.41689$ & $12.6000 \pm 0.50266$ & 1.868 & 0.004 \\
\hline SBP $[\mathrm{mg} \mathrm{Hg}]$ & $112.7259 \pm 1.07529$ & $116.8281 \pm 1.00013$ & 3.934 & 0.005 \\
\hline DBP $[\mathrm{mg} \mathrm{Hg}]$ & $72.1939 \pm 0.72891$ & $74.4984 \pm 0.67097$ & 9.250 & 0.026 \\
\hline
\end{tabular}

WC — waist circumference; BMI — body mass index; TG — triglycerides; TC — total cholesterol; HDL — high density lipoprotein; LDL — low density lipoprotein; FBG — fasting blood glucose; SBP — systolic blood pressure; DBP — diastolic blood pressure

Table 6. Comparison (mean \pm SD) of the clinical and biochemical characteristics in insulin-resistant and insulin-sensitive female individuals

\begin{tabular}{|l|c|c|c|c|}
\hline Variables & $\begin{array}{c}\text { TG/HDL } \leq \mathbf{3} \\
(\mathbf{n}=\mathbf{3 4 6})\end{array}$ & $\begin{array}{c}\text { TG/HDL }>\mathbf{3} \\
(\mathbf{n}=\mathbf{2 1 1})\end{array}$ & $\mathbf{F}$ value \\
\hline WC $[\mathrm{cm}]$ & $84.6908 \pm 0.59562$ & $91.5308 \pm 0.68886$ & 4.350 & 0.000 \\
\hline BMI $\left[\mathrm{kg} / \mathrm{m}^{2}\right]$ & $25.8013 \pm 0.27636$ & $28.0422 \pm 0.27304$ & 14.230 & 0.000 \\
\hline TG $[\mathrm{mg} / \mathrm{dL}]$ & $89.2075 \pm 1.33481$ & $193.8820 \pm 4.76650$ & 154.072 & 0.000 \\
\hline TC $[\mathrm{mg} / \mathrm{dL}]$ & $172.8957 \pm 1.79029$ & $197.7166 \pm 3.01460$ & 7.352 & 0.000 \\
\hline HDL $[\mathrm{mg} / \mathrm{dL}]$ & $49.9438 \pm 0.52805$ & $37.7616 \pm 0.55819$ & 7.823 & 0.000 \\
\hline LDL $[\mathrm{mg} / \mathrm{dL}]$ & $98.4184 \pm 1.22199$ & $115.7569 \pm 1.94344$ & 7.135 & 0.000 \\
\hline FBG $[\mathrm{mg} / \mathrm{dL}]$ & $94.8075 \pm 1.06864$ & $108.0668 \pm 2.97811$ & 41.222 & 0.000 \\
\hline Insulin $[\mathrm{mU} / \mathrm{mL}]$ & $11.3238 \pm 0.38298$ & $13.6519 \pm 0.45993$ & 0.585 & 0.000 \\
\hline SBP $[\mathrm{mg} \mathrm{Hg}]$ & $107.1821 \pm 0.91860$ & $113.6730 \pm 1.29037$ & 2.319 & 0.000 \\
\hline DBP $[\mathrm{mg} \mathrm{Hg}]$ & $68.1014 \pm 0.60911$ & $72.5118 \pm 0.86324$ & 3.906 & 0.000 \\
\hline
\end{tabular}

WC — waist circumference; BMI — body mass index; TG — triglycerides; TC — total cholesterol; HDL — high density lipoprotein; LDL — low density lipoprotein; FBG — fasting blood glucose; SBP — systolic blood pressure; DBP — diastolic blood pressure 
and high blood pressure [23]. The prevalence of both systolic and diastolic hypertension in our community-based study was about $10 \%$ of the total population, with no significant difference between men and women. Various studies have been carried out on the prevalence of HTN in different parts of Iran, which reported different rates [24]. A new systematic and meta-analytical review (based on studies published in national and international journals between 2004 and 2018) stated that the overall prevalence of HTN in Iranian society was $25 \%$ and the prevalence of HTN in older adults was $42 \%$ higher than other age groups [25]. The outcome of another cross-sectional study, which was conducted among 2,107 Iranian adult residents of Isfahan, has shown that the overall prevalence of HTN was $17.3 \%$ (18.9 and $15.5 \%$ in men and women) [26]. The highest prevalence of HTN was found to be $46.0 \%$ among adults in Africa, in contrast to $35.0 \%$ among American adults [27] and roughly $23.0 \%$ among Canadian adults [28]. In this study, the prevalence of HTN was lower than in similar studies [25-28]. The reason might be that normal population participated in our study, according to their reference to the center, because of the prevalence of HTN can be affected by demographic factors, such as age, race, gender and socioeconomic status, and type of study (cross-sectional or cohort study) [29]. In this study, the relationship between hypertension and insulin resistance was examined. The results showed that the mean of TG/HDL as an index of insulin-resistant was significantly different between untreated essential hypertensive and normotensive participants. This finding is consistent with most studies, which referred to the concurrence of hypertension and insulin resistance $[9,10]$. These two variables are the components of metabolic syndrome and often coexist [30]. It's estimated that about $50 \%$ of patients with essential hypertension have been suffering from insulin-resistant or hyperinsulinemia, and glucose intolerance. Also, up to $80 \%$ of patients with type 2 diabetes were hypertensive $[11,30]$. Clinical studies have shown a strong association between essential hypertension and insulin resistance/compensatory hyperinsulinemia. It should be noted the causal nature of them were not completely explained [16]. Some researchers suggest that insulin resistance and hyperinsulinemia are related to hypertension [22], while others do not support this theory [15]. High blood pressure and insulin resistance have important roles in the increase in cardiovascular diseases, cardiovascular (CVD) morbidity, and mortality rates [31]. Accordingly, the reduced risk of cardiovascular diseases is dependent on early detection and treatment of high blood pres- sure, correction of blood glucose level, and associated metabolism [32].

In this study, the WC, BMI, FBG, lipid profile, and fasting serum insulin levels were significantly higher in individuals with high blood pressure than in both normotensive and insulin-sensitive populations. This finding has been confirmed by similar studies [32]. Also, Garcia and its co-workers found abnormal glucose metabolism in hypertensive cases [29]. These risk factors induce and aggravate HTN and insulin resistance. In this regard, many studies have found the prevalence of metabolic syndrome to be higher in individuals with HTN than in the general population [33]. Additionally, the prevalence of HTN was higher in the insulin resistance patients. One of the reasons for this finding is that changes take place in the vascular walls associated with higher levels of plasma lipids that can accelerate arteriosclerosis and hypertension $[13,34]$. So, insulin resistance has been proposed as the main underlying cause of cardiometabolic syndrome $[9,10]$. Kim and et al. showed that four major risk factors for cardiovascular disease in nondiabetic Korean elderly individuals were glucose tolerance impairment, dyslipidemia, hypertension, and obesity [35]. Insulin resistance is also associated with high blood pressure in obese subjects. There are still some questions that remain unanswered whether high blood pressure alone was due to insulin resistance or not. Interestingly, sodium is a link between hypertension and insulin resistance. Some studies suggest that a high-salt diet impairs insulin sensitivity in hypertensive patients [36]. Insulin hypersecretion increases the reabsorption of sodium by activating the sympathetic system and alters blood pressure [37]. Of course, other mechanisms may include chronic inflammation and oxidative stress [32]. There are some degrees of chronic inflammation in obese people [37]. Also, excess nutrient intake can induce oxidative stress in the adipose tissue which is manifested by more secretion of inflammatory cytokine [38]. Furthermore, the coexistence of insulin resistance and hypertension prompt premature atherosclerosis [39]. It should be noted that all participants with high blood pressure and insulin resistance had a significantly higher waist and wrist diameters than normal individuals. It has been proven that normal blood pressure is controlled by substances that regulate vascular tone. Therefore, overweight, which often is associated with hyperinsulinemia, stimulates endothelin 1 (ET-1) production. It eventually causes an arterial disturbance. In normal physiological conditions, NO inhibits the ET-1 activity. Thus, the loss of endothelial-derived NO may increase the production of ET-1, which is important in the pathophysiology of hypertension [40]. 


\section{Conclusions}

The results of this study emphasize the positive correlation between hypertension and insulin resistance. Despite the latest progress in preventing non-communicable diseases, the prevalence of HTN in the world, especially in developing countries, is expanding.

\section{Acknowledgments}

This study was supported by a grant from the research department of the Qazvin University of Medical Sciences. The authors would like to thank the participants involved in this study and the department of research of the Qazvin University of Medical Science in endorsing the project.

\section{Conflict of interest}

Nothing to declare - the authors declare that they have no conflict of interests.

\section{References}

1. GBD 2017 Risk Factor Collaborators, GBD 2016 Risk Factors Collaborators. Global, regional, and national comparative risk assessment of 84 behavioural, environmental and occupational, and metabolic risks or clusters of risks, 1990-2016: a systematic analysis for the Global Burden of Disease Study 2016. Lancet. 2017; 390(10100): 1345-1422, doi: 10.1016/S0140-6736(17)323668, indexed in Pubmed: 28919119.

2. Patel P, Ordunez P, DiPette D, et al. [Improved Blood Pressure Control to Reduce Cardiovascular Disease Morbidity and Mortality: The Standardized Hypertension Treatment and Prevention Project]. J Clin Hyperten. 2016; 18(12): 1284-1294, doi: 10.1111/jch.12861, indexed in Pubmed: Improved Blood Pressure Control to Reduce Cardiovascular Disease Morbidity and Mortality: The Standardized Hypertension Treatment and Prevention Project.

3. Benjamin EJ, Blaha MJ, Chiuve SE, et al. American Heart Association Statistics Committee and Stroke Statistics Subcommittee. Heart Disease and Stroke Statistics-2017 Update: A Report From the American Heart Association. Circulation. 2017; 135(10): e146-e603, doi: 10.1161/CIR.0000000000000485, indexed in Pubmed: 28122885.

4. Rodgers A, Ezzati M, Vander Hoorn S, et al. Comparative Risk Assessment Collaborating Group, Comparative Risk Assessment Collaborating Group. Selected major risk factors and global and regional burden of disease. Lancet. 2002; 360(9343): 1347-1360, doi: 10.1016/S0140-6736(02)11403-6, indexed in Pubmed: 12423980.

5. Gaciong Z, Siński M, Lewandowski J. Blood pressure control and primary prevention of stroke: summary of the recent clinical trial data and meta-analyses. Curr Hypertens Rep. 2013; 15(6): 559-574, doi: 10.1007/s11906-013-0401-0, indexed in Pubmed: 24158454.

6. Chockalingam A. Impact of World Hypertension Day. Can J Cardiol. 2007; 23(7): 517-519, doi: 10.1016/s0828282x(07)70795-x, indexed in Pubmed: 17534457.

7. Lastra G, Syed S, Kurukulasuriya LR, et al. Type 2 diabetes mellitus and hypertension: an update. Endocrinol Metab Clin North Am. 2014; 43(1): 103-122, doi: 10.1016/j.ecl.2013.09.005, indexed in Pubmed: 24582094.

8. Harati H, Hadaegh F, Saadat N, et al. Population-based incidence of Type 2 diabetes and its associated risk factors: results from a six-year cohort study in Iran. BMC Public Health. 2009; 9: 186, doi: 10.1186/1471-2458-9-186, indexed in Pubmed: 19531260.

9. Naruse M, Koike Y, Kamei N, et al. Effects of azilsartan compared with telmisartan on insulin resistance in patients with essential hypertension and type 2 diabetes mellitus: An open-label, randomized clinical trial. PLoS One. 2019; 14(4): e0214727, doi: 10.1371/journal.pone.0214727, indexed in Pubmed: 30943275.

10. Zhou MS, Schulman I. Link between Insulin Resistance and Hypertension: What Have We Learned from Our Ancestors? J Autacoids. 2012; 1-e102, doi: 10.4172/2161-0479.1000e102.

11. Agata J, Miyazaki Y, Takada M, et al. Association of insulin resistance and hyperinsulinemia with disturbed lipid metabolism in patients with essential hypertension. Hypertens Res. 1998; 21(1): 57-62, doi: 10.1291/hypres.21.57, indexed in Pubmed: 9582109.

12. Czech MP. Insulin action and resistance in obesity and type 2 diabetes. Nat Med. 2017; 23(7): 804-814, doi: 10.1038/nm.4350, indexed in Pubmed: 28697184.

13. Sowers JR. Insulin resistance, hyperinsulinemia, dyslipidemia, hypertension, and accelerated atherosclerosis. J Clin Pharmacol. 1992; 32(6): 529-535, doi: 10.1177/009127009203200607, indexed in Pubmed: 1634639 .

14. Roberts CK, Hevener AL, Barnard RJ. Metabolic syndrome and insulin resistance: underlying causes and modification by exercise training. Compr Physiol. 2013; 3(1): 1-58, doi: 10.1002/cphy. c110062, indexed in Pubmed: 23720280.

15. Petrie JR, Guzik TJ, Touyz RM. Diabetes, Hypertension, and Cardiovascular Disease: Clinical Insights and Vascular Mechanisms. Can J Cardiol. 2018; 34(5): 575-584, doi: 10.1016/j. cica.2017.12.005, indexed in Pubmed: 29459239.

16. El-Atat F, McFarlane SI, Sowers JR. Diabetes, hypertension, and cardiovascular derangements: pathophysiology and management. Curr Hypertens Rep. 2004; 6(3): 215-223, doi: 10.1007/s11906004-0072-y, indexed in Pubmed: 15128475.

17. Zamanian RT, Hansmann G, Snook S, et al. Insulin resistance in pulmonary arterial hypertension. Eur Respir J. 2009; 33(2): 318-324, doi: 10.1183/09031936.00000508, indexed in Pubmed: 19047320.

18. Fazizi F, Esmaillzadeh A, Mirmiran FP. Obesity and cardiovascular disease risk factors in Tehran adults: a population-based study. East Mediterr Health J. 2004; 10(6): 887-897, indexed in Pubmed: 16335777.

19. Bahrami H, Sadatsafavi M, Pourshams A, et al. Obesity and hypertension in an Iranian cohort study; Iranian women experience higher rates of obesity and hypertension than American women. BMC Public Health. 2006; 6: 158, doi: 10.1186/1471-2458-6158, indexed in Pubmed: 16784543.

20. Zamanian RT, Hansmann G, Snook S, et al. Insulin resistance in pulmonary arterial hypertension. Eur Respir J. 2009; 33(2): 318-324, doi: 10.1183/09031936.00000508, indexed in Pubmed: 19047320.

21. Salazar MR, Carbajal HA, Espeche WG, et al. Comparison of the abilities of the plasma triglyceride/high-density lipoprotein cholesterol ratio and the metabolic syndrome to identify insulin resistance. Diab Vasc Dis Res. 2013; 10(4): 346-352, doi: 10.1177/1479164113479809, indexed in Pubmed: 23624761.

22. Hossain P, Kawar B, El Nahas M. Obesity and diabetes in the developing world--a growing challenge. N Engl J Med. 2007; 356(3): 213-215, doi: 10.1056/NEJMp068177, indexed in Pubmed: 17229948.

23. Abebe SM, Berhane Y, Worku A, et al. Diabetes mellitus in North West Ethiopia: a community based study. BMC Public Health. 2014; 14: 97, doi: 10.1186/1471-2458-14-97, indexed in Pubmed: 24479725.

24. Yazdanpanah L, Shahbazian H, Shahbazian H. Prevalence, awareness and risk factors of hypertension in southwest of Iran. J Renal Inj Prev. 2015; 4(2): 51-56, doi: 10.12861/jrip.2015.11, indexed in Pubmed: 26060838. 
25. Oori MJ, Mohammadi F, Norozi K, et al. Prevalence of HTN in Iran: Meta-analysis of Published Studies in 2004-2018. Curr Hypertens Rev. 2019; 15(2): 113-122, doi: 10.2174/15734021 15666190118142818, indexed in Pubmed: 30657043.

26. Eghbali M, Khosravi A, Feizi A, et al. Prevalence, awareness, treatment, control, and risk factors of hypertension among adults: a cross-sectional study in Iran. Epidemiol Health. 2018; 40: e2018020, doi: 10.4178/epih.e2018020, indexed in Pubmed: 29807408.

27. World Health Organization. World Health Day 2013: measure your blood pressure, reduce your risk. www.who.int/ mediacentre/ news/ releases/2013/world_health_day_20130403/en/ (2018 Jun 4).

28. Robitaille C, Dai S, Waters C, et al. Diagnosed hypertension in Canada: incidence, prevalence and associated mortality. CMAJ. 2012; 184(1): E49-E56, doi: 10.1503/cmaj.101863, indexed in Pubmed: 22105752.

29. Lloyd-Jones D, Adams R, Carnethon M. Epidemiology of hypertension. In: Bakris GL, Sorrentino MJ. ed. Hypertension: A Comanion to Braunwald's Heart Disease. 2nd Ed Elsevier Inc 2012: 488

30. Zhou MS, Schulman IH, Zeng Q. Link between the renin-angiotensin system and insulin resistance: implications for cardiovascular disease. Vasc Med. 2012; 17(5): 330-341, doi: 10.1177/1358863X12450094, indexed in Pubmed: 22814999.

31. Cheung BMY, Li C. Diabetes and hypertension: is there a common metabolic pathway? Curr Atheroscler Rep. 2012; 14(2): 160-166, doi: $10.1007 / \mathrm{s} 11883-012-0227-2$, indexed in Pubmed: 22281657.

32. Sinha S, Akhter Q, Banik S, et al. Correlation Study of Insulin Resistance and Essential Hypertension among Bangladeshi Male Volunteers. J Young Pharmac. 2015; 7(3): 200-205, doi: 10.5530/jyp.2015.3.10.
33. Mulè G, Calcaterra I, Nardi E, et al. Metabolic syndrome in hypertensive patients: An unholy alliance. World J Cardiol. 2014; 6(9): 890-907, doi: 10.4330/wjc.v6.i9.890, indexed in Pubmed: 25276291.

34. Rafieian-Kopaei M, Setorki M, Doudi M, et al. Atherosclerosis: process, indicators, risk factors and new hopes. Int J Prev Med. 2014; 5(8): 927-946, indexed in Pubmed: 25489440.

35. Kim $\mathrm{HK}$, Kim $\mathrm{CH}$, Kim EH, et al. Impaired fasting glucose and risk of cardiovascular disease in Korean men and women: the Korean Heart Study. Diabetes Care. 2013; 36(2): 328-335, doi: 10.2337/dc12-0587, indexed in Pubmed: 23002083.

36. Kong YW, Baqar S, Jerums G, et al. Sodium and Its Role in Cardiovascular Disease - The Debate Continues. Front Endocrinol (Lausanne). 2016; 7: 164, doi: 10.3389/fendo.2016.00164, indexed in Pubmed: 28066329.

37. Alcalá M, Sánchez-Vera I, Sevillano J, et al. Vitamin E reduces adipose tissue fibrosis, inflammation, and oxidative stress and improves metabolic profile in obesity. Obesity (Silver Spring). 2015; 23(8): 1598-1606, doi: 10.1002/oby.21135, indexed in Pubmed: 26148343.

38. Janus A, Szahidewicz-Krupska E, Mazur G, et al. Insulin Resistance and Endothelial Dysfunction Constitute a Common Therapeutic Target in Cardiometabolic Disorders. Mediators Inflamm. 2016; 2016: 3634948, doi: 10.1155/2016/3634948, indexed in Pubmed: 27413253.

39. Longo M, Zatterale F, Naderi J, et al. Adipose Tissue Dysfunction as Determinant of Obesity-Associated Metabolic Complications. Int J Mol Sci. 2019; 20(9), doi: 10.3390/ijms20092358, indexed in Pubmed: 31085992.

40. Orlando A, Viazzi F, Giussani M, et al. Endothelin-1/nitric oxide balance and HOMA index in children with excess weight and hypertension: a pathophysiological model of hypertension. Hypertens Res. 2019; 42(8): 1192-1199, doi: 10.1038/s41440019-0253-3, indexed in Pubmed: 30923371. 